\title{
REGIONAL INPUT-OUTPUT ANALYSIS: A COMPARISON OF FIVE "READY-MADE" MODEL SYSTEMS
}

\author{
Sharon M. Brucker, Steven E. Hastings and William R. Latham, II*
}

\section{Introduction}

In order to understand the current state of the art of regional input-output modeling, it is useful to have a feeling for both its recent historical development and the characteristic of current models. In the following section we outline, in the most general way, how the practice of regional input-output modeling has evolved over the last 25 years from an esoteric pastime of the academy to the competitive, market-oriented state in which we find it today. Then we describe some salient characteristics of the products and participants found in that market as we see it. Next we identify five particular products whose characteristics are compared in the rest of the paper. ${ }^{1}$ Following the comparisons, we offer some tentative conclusions and suggest potentially fruitful avenues for future research.

\section{A Brief History}

Significant changes have occurred in regional input-output modeling over the last 25 years. At one time, a regional I-O model frequently meant a surveybased regional I-O model. Production of such a model was such a formidable undertaking (as was evident from reading Isard's Methods ${ }^{2}$ or the multiple volumes on the Philadelphia I-O project) ${ }^{3}$ that it was possible only for those with access to huge (for those days) computers, large numbers of graduate students to collect and analyze data, and a dedicated, highly-trained staff of professionals. These requirements often meant that the activity had to be centered in a regional science department with access to external funding.

Researchers without these resources, but with needs to perform regional impact analysis, were frustrated with the requirements of survey-based models. Their search for new methodologies filled the literature with short-cut, less expensive, non-survey methods. ${ }^{4}$

Gradually the growing acceptance of non-survey methods led the more adventuresome researchers to produce complete, non-survey regional I-O tables. Success in such an effort often hinged on having a professional on the staff who had worked on an I-O model previously. Such models remained much as the

\footnotetext{
*Research Associate and Associate Professor, Department of Agricultural and Food Economics, Delaware Agricultural Experiment Station, College of Agricultural Services and Associate Professor, Department of Economics, University of Delaware. Published as Miscellaneous Paper No. 1188 of the Delaware Agricultural Experiment Station.
}

survey models they sought to supplant: infrequently found and, when found, far out of date.

Soon, however, changes in technology and markets wrought significant changes in the market for regional input-output analysis. The demand for regional models was increased tremendously by federal, state and local environmental agencys' requirements for regional environmental impact statements; by concern for rural development in the U.S.D.A.; and by the need, in Congress and in other agencies, to understand the regional implications of changes in defense programs as well as other economic, political and demographic changes.

Many of these new demands for regional models arose in splendid, unconscious isolation and spawned project after project with large-scale funding specifically directed at the development of a "portable" means of calculating the economic impacts of this or that contemplated change. 5 The portability requirement most often meant that a methodology should be applicable in any region in which the particular sort of impact under investigation might occur. Thus, coastal zone impact systems should be applicable to any coastal area; community development models should be applicable to any community; and military expenditure impact models should apply to any military spending in any area. Impact assessment systems were developed which were indeed portable, but often only if the appropriate analyst was also transported along with the model. Models developed and demonstrated in one region for one purpose were seldom applied to other regions or to other purposes. Duplication of modeling efforts by different agencies for the same regions or by the same agencies for the same region at different times was not unusual. Many short-cut methods and ad hoc procedures were developed. Non-survey regional I-O was among the more expensive methods available. The chaos we know to be indicative of a free market with little information prevailed. It was time for the invisible hand to make its mystical appearance and to begin to impose order on this market.

This expansion of the market permitted specialization in the production of regional models with concomitant decreases in the average cost of production of these models in comparison with the costs of the other less sophisticated methods. These cost decreases resulted in significant measure from the simple economies of scale achievable in the process of producing a large number of similar non-survey, regional I-O models. In addition, a phenomenal fall in computing costs contributed a downward shift to average production costs. Finally, the adoption of some 
technical innovations, such as the calculation of multipliers without inversion, contributed to further cost decreases. Truly, portable input-output modeling strategies were now available.

In general, these new model systems provided a pattern or model of how to estimate an I-O model for a region using data available for any region; but they often still required quite a bit of know-how on the part of the researcher. The most recent development in the market has been the introduction of "ready-made" models which require little or no knowledge on the part of the user.

Since the advent of the Regional Input-Output Modeling System (RIMS) ${ }^{6}$ at the Department of Commerce, the casual regional scientist or planner has been able to buy, for a relatively modest fee, ready-made or pre-fabricated input output multipliers for his region. Other suppliers rapidly entered the "ready-made" market, notably the Regional Science Research Institute. ${ }^{7}$

Recently, due again to changes in demand and technology, this time in the form of micro computing capacity, we have witnessed another innovation, the "doit-yourself" model. ${ }^{8}$ Naturally, as with all do-ityourself projects, this one requires much more work from the user than a ready-made model but has the usual benefit of lower monetary cost.

With both ready-made and do-it-yourself models, there is concern for quality in comparison with custom designed and constructed models. The availability and use of ready-made and do-it-yourself regional I-O models has introduced the possibility of complex, sophisticated models being used inappropriately in simple-minded ways.

Along with cost reductions in the production of models made possible by the expanded scale of production required to meet an increased demand, it has also become worthwhile for modelers to invest more time and effort into the development of more sophisticated model systems. In the market for regional input-output modeling systems, product differentiation through the availability of options and additional features has become an important form of non-price competition. The users of these more complex modeling systems are now progressively less likely to be the designers or builders of them. In fact, the distance between users and modelers seems to be increasing.

In this regard, regional input-output modelers are in much the same position as were econometric modelers a few years ago as econometric models and methods outdistanced the sophistication of a widening market of users. In the case of the econometric models, the communication problem has been left largely unresolved. The models and methods remain in the "black boxes" in which users purchase them. Fortunately for users of econometric models, the consequences of their ignorance are often small because the differences among the major econometric models are relatively small. Also, in the econometric modeling market, a small number of well-known firms dominates the market and the smaller competitors are forced to deal with the reality of most users having some awareness of the characteristics of the dominant firms' products. These characteristics do not apply to the market for regional input-output modeling systems. The vendors are more numerous and neither they nor their products are as well-known as are the vendors of econometric models. Consequently, the variety in the products and services being offered is large, and there is no set of "industry standards" to which all modelers must adhere.

Thus, in the regional input-output market, it may be more important for users to learn more clearly from modelers exactly what the products and properties of the various model systems are. As is often the case in other markets as well, the market for regional inputoutput models lacks information necessary to promote efficiency, and information that is available is costly to obtain.

\section{Goals of the Paper}

A major purpose of this paper is to contribute to a reduction in the cost of obtaining and processing relevant information about the regional input-output modeling market. To do so, we first develop a structure for making meaningful model comparisons. We hope to both make potential users aware of the characteristics of many of the alternatives now available in the market for ready-made I-O models and to indicate how useful comparisons can be made. Then we demonstrate the utility of this approach to model evaluation by applying it to a small number of model systems.

A second purpose of this paper is to inform researchers, perhaps including some of those researchers whose models are included in the comparisons, of the current state of the art for such model systems. We hope that this comparison will stimulate further refinements and development in the same way that exchanges of information through trade associations stimulate progress in other industries. Competitive market theories lead us to expect that more information in the market will result in an even wider range of choices for analysts, both in the style of I-O analysis and in the functions the analysis can perform.

A third purpose of the paper is to encourage communication, exchange and cooperation among all 
the participants in the market for ready-made regional models. Specialization can free up resources previously devoted to duplicative efforts. For example, with telephone transfers of data and models now so readily accomplished, the transportation cost on inputs and products in the market for regional models has fallen precipitously. We would expect that agglomeration economies in the form of localization economies would now be available. Specialists should find it profitable to gain economies of scale in providing commonly used inputs or services to the whole market. The funtions of the modeling firm can now be geographically separated. Users or even modelers may no longer have to invert their own matrices, write their own regionalization or aggregation programs, or maintain their own data bases. If these products and services were available elsewhere in the market as distinct purchasable commodities, analysts could spend more time in collecting primary effects data and in carefully interpreting the results of using the models. In this way, the final product of the modeling process can change to be what it was always meant to be -- the analysis -- and not the model itself. Thus, if interactions among modelers and users are effective, the product itself may improve and become more useful.

\section{Comparing I-O Model Systems}

Among the characteristics of models in which we think users are interested (or will be interested once they learn of their significance) are: (1) their flexibility in use, (2) the clarity of descriptions of their inputs and interpretations of their products, (3) their believability, and (4) their costs. Researchers and modelers will be more interested in costs and in the characteristics of the product.

\section{Scope of the Investigation}

An increase in the range of model forms and functions is clearly evident in the large number of model systems that exist today: These systems include not only region-specific models but a wide range of model systems available as "portable" and even "readymade" for any and all regions. It would be useful to examine all the models that are available to regional scientists to use for I-O type impact analysis in various regions of the U.S. However, the number of such models is too large, and their structures and features are too diverse to embrace them all in a single paper. Thus the comparisons in this paper include only those models which provide regional I-O models for all the regions in the U.S. Excluded are all the linked econometric, demographic and community impact models that have an I-O block in them. They are obviously important tools which simply are beyond the scope of our present comparisons. A logical future extension of this study would be to include these linked models.

\section{Methodology}

Presently available published materials about the model systems often provide an insufficient basis for the kinds of comparisons we thought were relevant. These materials do not address some of our concerns, and, even when they seem to do so, problems of terminology and interpretation remain. Thus only a survey of the model builders themselves will suffice as a means of assembling the data base required for the comparisons.

The survey conducted for this paper provides information about the characteristics of five major model systems. Because there are others available, these five are presented as representative of the available choices.

A preliminary questionnaire was designed and mailed to several regional I-O modelers for their comments. A revised questionnaire (available from the authors on request) was initially sent to eight modelers. All were cooperative, but several could not participate because of other commitments or model incompatibilities. The five who participated fully in the project and their models are: $\underline{\text { Model }}$

ADOTMATR

IMPLAN

RIMS II

\section{$\underline{\text { Representative(s) }}$}

Charles Lamphaer

Ronald T. Komecny

Gregory Alward

Richard Beemiller

Zoe Ambargis $\underline{\text { Affiliation }}$

University of Nebraska

\section{U.S. Forest Service}

Department of Commerce, BEA 


$\begin{array}{lll}\text { Model } & \underline{\text { Representive(s) }} & \text { Affliation } \\ \text { RSRI } & \text { Benjamin Stevens } & \text { Regional Science Research Institute } \\ \text { SCHAFFER } & \text { William Schaffer } & \text { Georgia Institute of Technology }\end{array}$

Other modelers who were initially contacted and who were helpful in the early stages of the study include: Karen Polenske, MRIO; Jack Faucett, Faucett Associates; George I. Treyz, Regional Economic Models, Inc.; and Curtis Harris, University of Maryland.

The remainder of the paper is divided into four parts: 1) a brief description of the five models; 2) a comparison of the five models from a user's point of view, addressing the issues of flexibility, output format and user costs; 3) a discussion of the general characteristics of the models' structures; and 4) some conclusions regarding the use and construction of readymade models and implications for future research.

\section{Description of Models}

All of the models compared provide non-survey, input-output models for regions defined as counties or groups of counties. They are all based on the 1977 national I-O tables. Some use the national direct requirements, and some use the transactions. All of the models conduct the regionalization while the national data is still at a high level of disaggregation (more than 500 sectors). Beyond this point, the similarities among the models are few.

\section{RIMS II 9}

RIMS was designed by the Bureau of Economic Analysis to provide input-output type multipliers for any region of one or more contiguous counties at a 478 industry level of disaggregation: RIMS II now provides the disaggregated total requirements table and earnings effects as well as the multipliers. The estimates are the results of a three-step process: 1) a regionalizaiton of the technical coefficients from the 1977 national I-O table using a mixed location quotient approach; 2) a regionalization of household rows and column to adjust for regional consumption, savings and tax rates; and 3) a Leontief inversion process. ${ }^{10}$ Since BEA has access to much earnings and employment data which is undisclosed for other users, they can maintain a high level of disaggregation even at the county level.

\section{RSRI 11}

The Regional Science Research Institute model uses regional purchase coefficients (RPC'S) to adjust the 1977 national I-O technical coefficients to the region desired. A regional purchase coefficient is the proportion of a good or service used to fulfill its demands in a region which is supplied by the region to itself rather than being imported. RPC's are based on estimates from regression equations.

The model can estimate the impacts from any vector of changes in either final demand or output as defined by the user. Program products includes output, wage, employment, value added, and tax impacts of the given vector of changes. The employment impact can also be given in terms of disaggregated occupations. There are also options to estimate tourism impacts and administrative and auxiliary effects. Multipliers for wages, value added and employment are included. The model estimates these impacts using the iterative rather than matrix inversion technique; therefore, round-byround impacts can also be provided.

\section{ADOTMATR $^{12}$}

ADOTMATR is a computer program which enables the construction of non-survey regional or multiregional input-output models. The program also includes many options to assess various types of economic impacts. It was first programmed for a mainframe computer at the University of NebraskaLincoln, but the version used for this comparison is software for an IBM-PC (or compatible) microcomputer. ADOTMATR depends on a "reference" economy to construct the regional model. Since the most common reference economy to be used is the 1977 national I-O Table, the 1977 national Use and Make Tables $^{13}$ are two of the data files that come with ADOTMATR. However, other reference economies can be used, such as an existing state table.

After regionalizing the reference economy, using regional employment data or other regional data, ADOTMATR products include a direct requirements table; total requirements tables with and without households included; output, income, and employment multipliers; and a transaction table (if total output data is entered). The program provided routines: to compensate for price changes in the national tables; to adjust for industry mix differences; and to use either Location Quotient or RPC methods to more accurately represent local purchase patterns. The region can be any geographic specification depending on data availability. 


\section{IMPLAN ${ }^{14}$}

IMPLAN is a mainframe computer program for estimating regional I-O models. It regionalizes the 1977 national I-O transactions using a supply-demand pool technique (a new version available in mid-1986 will use RPC's).

To use the program a user must have access to a computer terminal with communications capabilities and a federal computer account for a Ft. Collins Colorado U.S. Forest Service computer. Once accessed, the user must supply sector definitions, and may also provide regional data where available. The program products are provided on-line to the user. The products include a transactions table, direct requirements table and Type-I output and income multipliers.

\section{SCHAFFER 15}

William Schaffer's Generic model is essentially the Georgia I-O model framework used for any other region. It also regionalizes the most disaggregated version of the 1977 national I-O model by incorporating regional data for ratios of local to national employment in the producing sectors and a ratio of local to national personal income for the consumers. To adjust for regional trade patterns, the model uses the supplydemand pool method modified to include Department of Transportation data. All work is done on the disaggregated table and then aggregated for presentation of results. The multiplier effects are estimated using the iterative process.

The products for the user can include a transactions table, direct requirements table and multipliers. Usually, just the vector of impacts is provided.

\section{Costs and Flexibility}

The comparisons which follow suppose that a potential user is contemplating use of one of the models to access the impacts of some change or changes in a regional economy. Table 1 presents a comparison of the models' costs, both monetary and time, as well as some of the features of interest to users. It is interesting to speculate that these models were indeed designed by regional scientists who are also entrepreneurs who know the value of differentiating a product. Each model seems to have some unique characteristics that no doubt appeal to a specific market.

In terms of monetary cost, ADOTMATR and IMPLAN are the lowest; ADOTMATR costs only $\$ 300$ for PC diskettes to do both initial model construction as well as individual impact estimation. IMPLAN's cost is less clearly defined, but a rough estimate of computer costs to initially custom design the model is about
\$220-\$310. This cost would cover many runs within a month's time. It would also cost about $\$ 87$ (for a month of use) for additional runs more than two months after the initial design. IMPLAN has no other charges but it does require that a federal account be established for computer charges. Naturally, the costs of using either ADOTMATR or IMPLAN also would include the overhead costs of acquiring and using either a PC or online terminal of some sort. No dollar value for this start-up cost has been included in Table 1 .

The other three options cost more money up front. RIMS II costs $\$ 1500$ for a new user purchasing the full model for one region. If more than one region is done at one time, each additional region costs between $\$ 560$ and $\$ 750$, depending on how many, overall, are being done. However, there is no additional run fee for RIMS II because the whole total requirements table is included, and, therefore, future impact analysis can be conducted by the user from the table. Schaffer's model has a similar pricing mode, the entire model is provided and, therefore, a one-time cost of $\$ 2000-\$ 3000$ is incurred. The RSRI model will provide four runs for a fee of $\$ 2,500$. This charge provides detail about the particular impact to be analyzed but does not provide a full table or set of multipliers. However, the full model can be purchased $(\$ 5,000$ for a PC or $\$ 10,000$ for the mainframe). This cost would then be a one-time expense which would allow further analysis of the particular region.

The above comparison of prices is misleading without discussion of time costs. Although RIMS II, RSRI and SCHAFFER have the highest prices, they each entail very little of the user's time. In each case, some interaction is necessary to define the region and the disturbance to be analyzed, but no further user time is necessary to acquire the impact estimates (with the possible exception of time to do some multiplication for RIMS II). On the other hand, ADOTMATR and IMPLAN both require quite a bit of time from the user: time to input data files into the computer, time to collect data if not available (i.e. employment data for ADOTMATR); time to call for runs and interact with software, albeit friendly. Once again overhead costs come into play. If a user is already familiar with data file manipulation on the mainframe or with software use on a microcomputer then these costs of investing in human capital will have already been made and the marginal cost of use will be low.

The length of wait for the model will vary depending on which model is chosen, but all will be considerably shorter (probably by a magnitude of years) than doing the entire model by oneself. The figures given in Table 1 are those reported by the various 


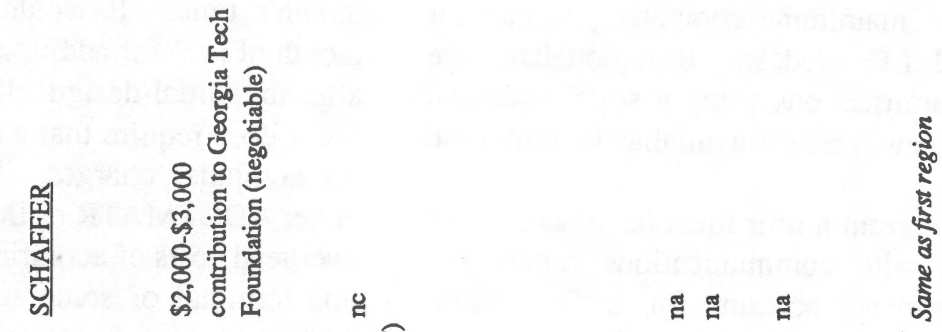

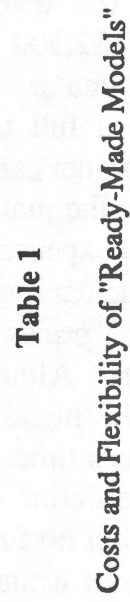

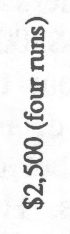

ถูำ

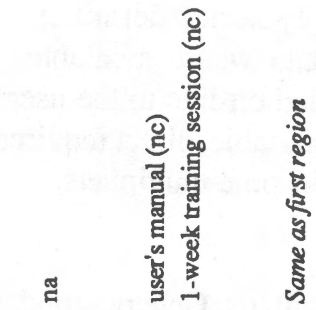

원
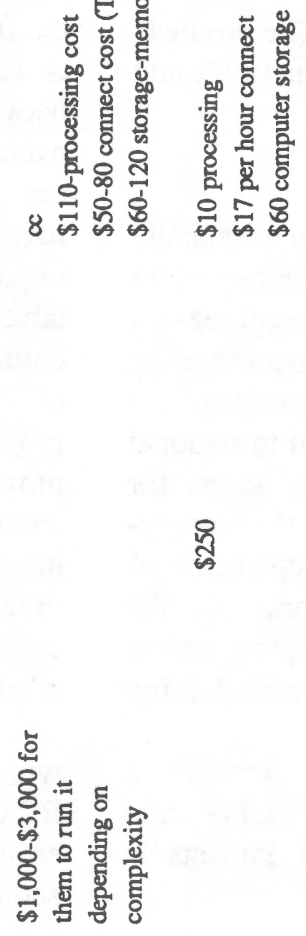

춿
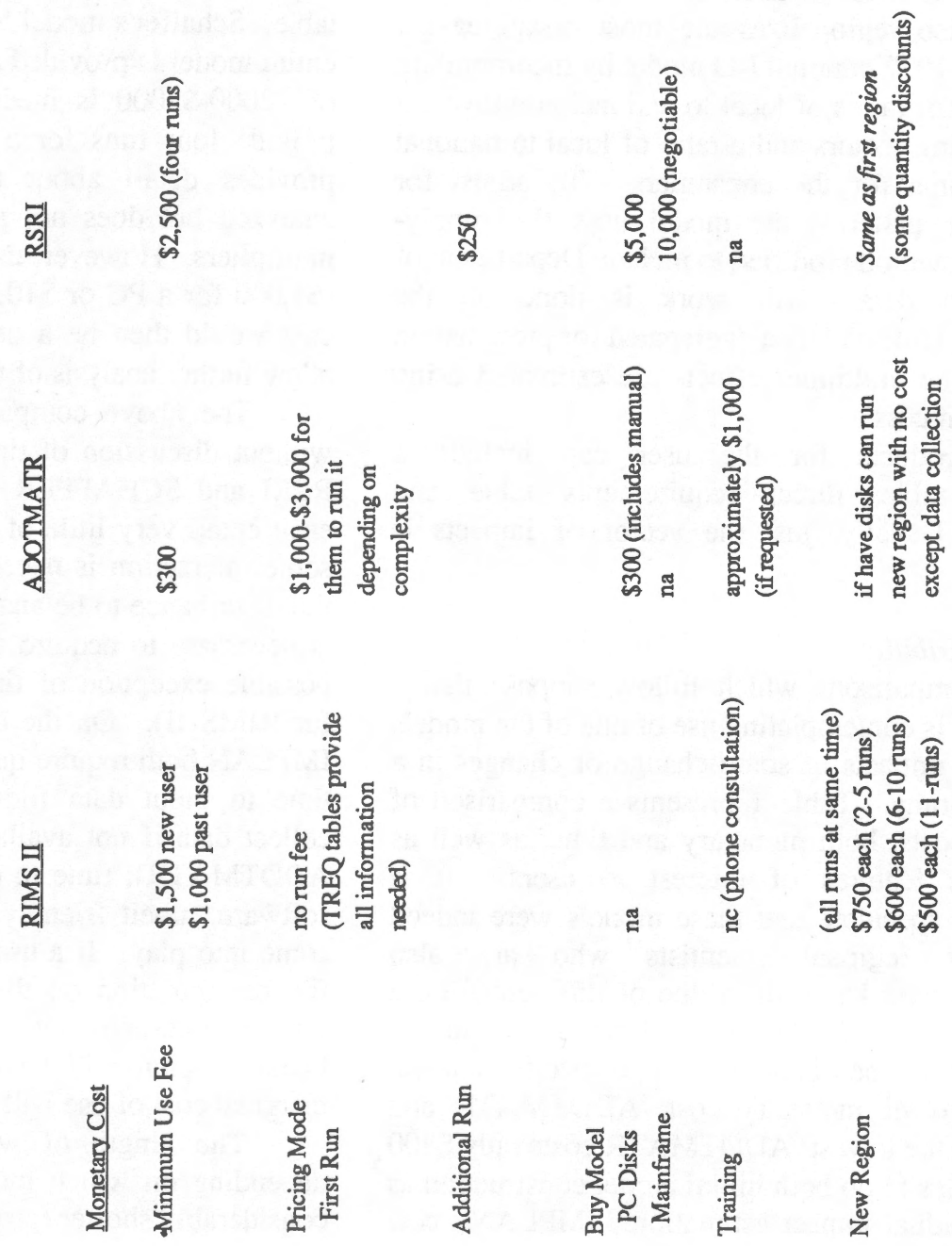

量

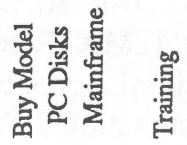

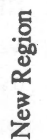




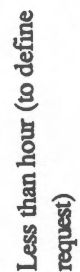

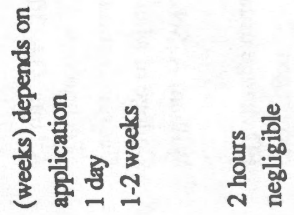

总

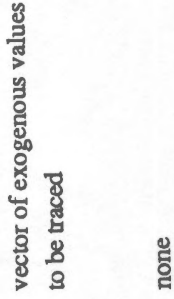

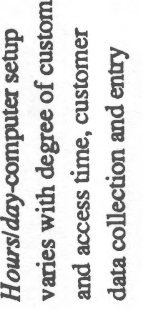

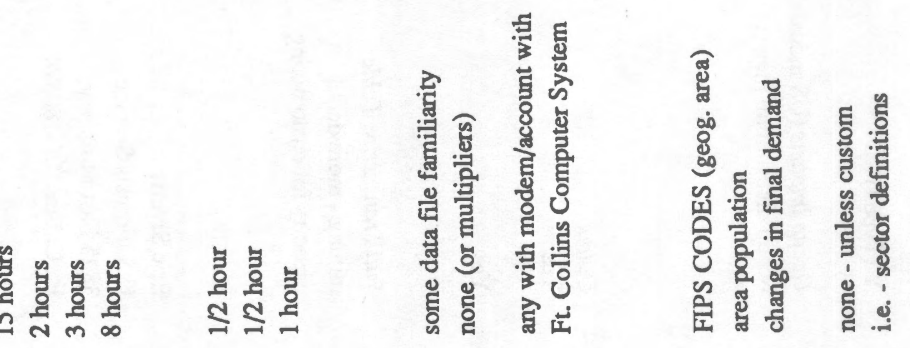

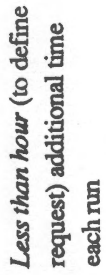

票县

ํㅜㄹ

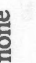

章
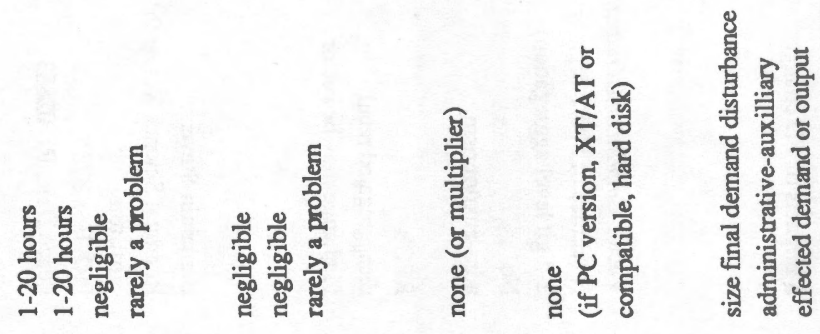

:
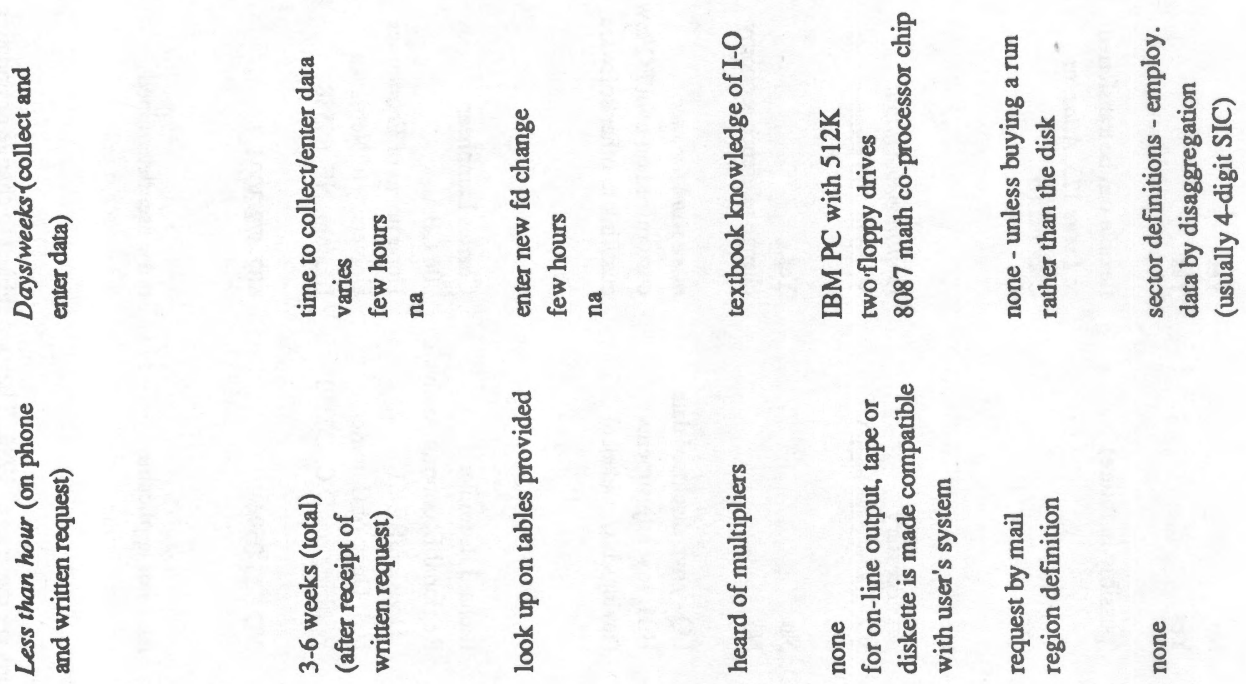

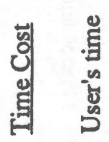
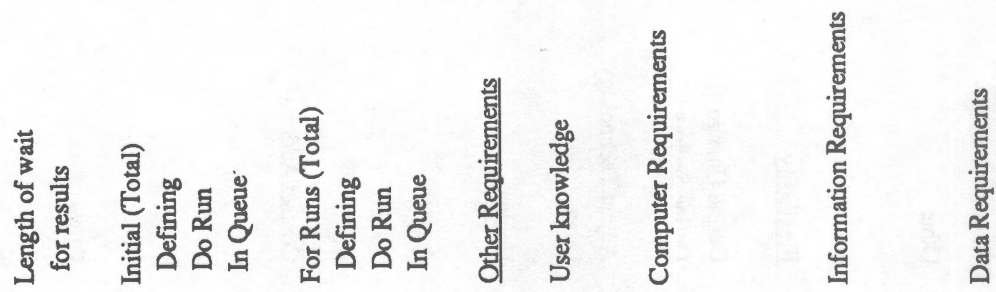
8

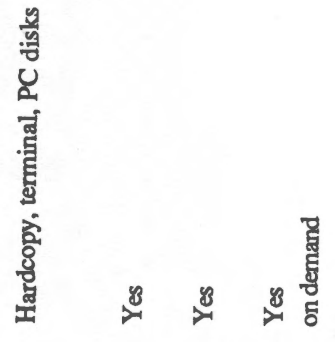

The Review of Regional Studies



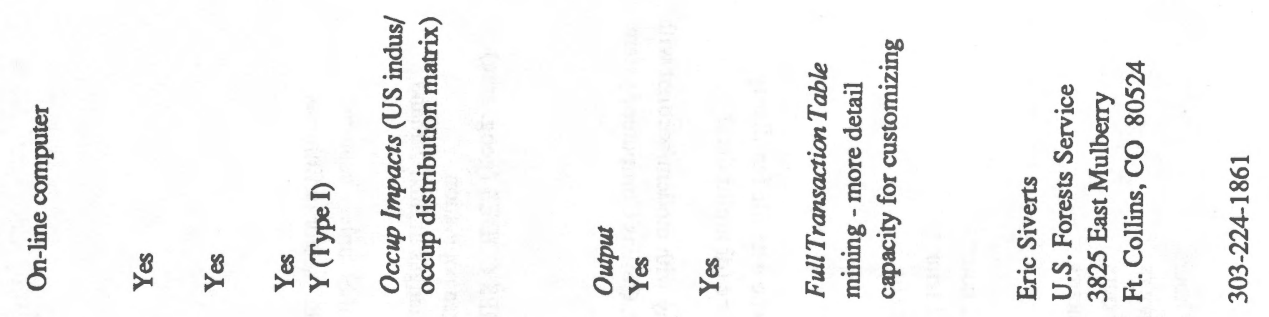

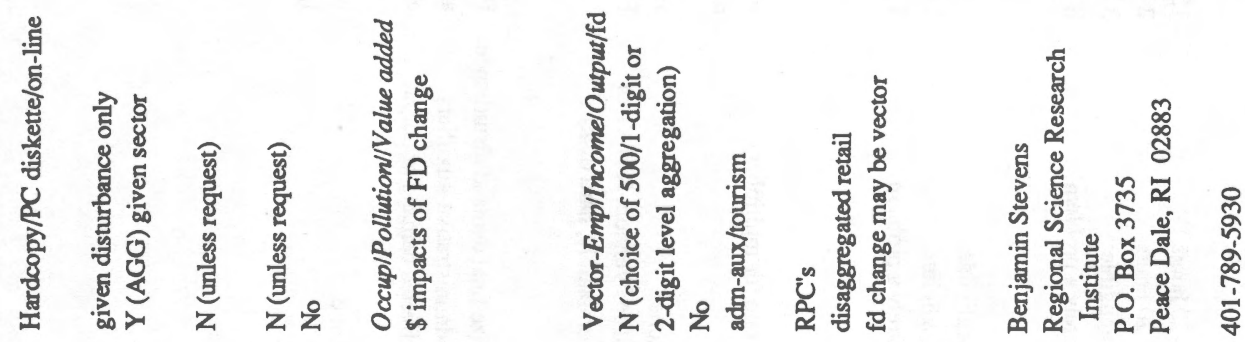




modelers themselves. It should be noted that once a model is "up" on a computer, the time to access it and get an additional run (or look up the multipliers for RIMS II) should be very short regardless of which model is chosen. Therefore, most of the differences in time for results will be in the initial stages. Not too suprisingly, ADOTMATR, which had the lowest price, would probably take the longest to build. At a minimum, time is required to collect and enter employment data and to enter sector definitions; for greater customization, there would be additional data needed. IMPLAN only requires Federal Information Processing Standards (FIPS) ${ }^{16}$ codes, area populations, sector definitions and the changes in final demand; however, additional data may be needed for customization of technology. IMPLAN's estimate of 15 hours does not include time to set up a computer account with Ft. Collins and get familiar with the system. This process could entail a week or two. RIMS II and SCHAFFER both report a few weeks as length of wait; RSRI reports less than 20 hours. All probably depend on other work in progress, and RIMS II has explicitly allowed for that in their estimate.

In addition to monetary and time costs, there are other inputs that are essential to acquire an input-output model for a region. The level of expertise required to use the models varies somewhat. Although all but ADOTMATR claim that having heard of a multiplier would be enough knowledge for a user, using IMPLAN does necessitate some familiarity with computer data file manipulation. ADOTMATR definitely requires the most know-how, at least a textbook knowledge of I-O and some familiarity with a microcomputer. Neither SCHAFFER, RIMS II nor RSRI require any computer knowledge or hardware. However, as hardware and know-how become more universally available, the convenience of having a model accessible on a microcomputer has led all the models to provide results usable on a personal microcomputer.

In terms of data, once again only ADOTMATR requires input of data by the user. However, some users of IMPLAN may want to utilize its customizing capacity which will require some data. Both RSRI and SCHAFFER require the nature and size of the final demand disturbance, while RIMS II only requires the definition of the region.

Most users will make their decision in part on the basis of the nature of the products provided by the model. The format of the products can be hard copy, diskette or tape for RIMS II. Similarly, RSRI and SCHAFFER offer hard copy, diskette or on-line transmission of results. IMPLAN requires a computer terminal to access results, while ADOTMATR requires an IBM compatible microcomputer. Therefore, someone with an IBM-PC could have access to all but IMPLAN, while someone with a mainframe terminal could have access to all but ADOTMATR. Someone with no computer could get hardcopy from RIMS II, RSRI or SCHAFFER.

The nature rather than the format of the products is where the greater diversity occurs. Although all the models send some form of multipliers, RSRI sends multipliers and impacts only for the disturbance vector and not a full table. Of all the models only IMPLAN sends a transactions table as standard output. However, SCHAFFER will send one on request, and ADOTMATR can generate one if additional total output data is entered. IMPLAN, ADOTMATR and SCHAFFER generate direct requirement tables. Only RSRI does not provide a total requirements table; while IMPLAN's table includes only direct and indirect impacts, not induced effects (Type I). Although RSRI's results are only for the disturbance vector, they along with SCHAFFER are the only models set up to easily estimate the impacts of a vector of changes rather than a final demand change in one sector at a time. At this point, only RSRI has the impacts by occupation; although RIMS II plans to add this feature in the future, and IMPLAN has a routine which can generate this impact if the industry/occupation distribution matrix is entered as a data file. RSRI can also provide pollution and value added impacts. ADOTMATR output can link to other PC software and thus can be presented in graphic and chart form.

A final characteristic in which a potential user may be interested is the flexibility of the model. Does the change whose impact is to be assessed have to be defined as a change in final demand? IMPLAN is set up for the disturbance to be entered as a change in output and SCHAFFER as a change in final demand. Both ADOTMATR and RSRI can accomodate changes in employment, income, final demand, or output, and RSRI can estimate impacts of some combination of the above. RIMS II allows the user to do the analysis but will explain how to use the tables with changes in final demand or income. All of the models except RSRI give some user choice in sector definition, but RIMS II and SCHAFFER do not do so routinely. RSRI offers a full 500 sector model so that any sector can be found. Only in ADOTMATR and IMPLAN are there automatic routines to adjust for unique or regional technologies by entering additional data.

It seems evident that choices of a regional readymade I-O model will be based on much more than price. Ceteris are certainly not paribus. If a user has computer knowledge and regional employment data, the choice is 
likely to be different than if the user needs to know the impact of vector of changes and needs to know in two weeks. The choice is likely to be different still if the user needs to analyze the impact on earnings of different changes each month for five different regions.

\section{Model Characteristics and Methodology}

Although the initial description of all the models indicates similarities, there are some fundamental differences in the methodologies. As can be seen in Table 2, all the models are based on the 1977 national I$\mathrm{O}$ table and allow for one time period. However, they have been updated in different ways. RIMS II has a yearly update of both the location quotients and wage data, while RSRI has updated employment and wages in 1983 and re-estimated their RPC's with 1983 transportation data. SCHAFFER updates his model with County Business Pattern and Personal Income data. ADOTMATR has a price updating routine. ${ }^{17}$

All of the models work with a large number of disaggregated sectors which are compatible with the national sectors. All of the models complete regional adjustments for industry mix and regional purchase patterns prior to the aggregation process. In fact, all but ADOTMATR and SCHAFFER do not aggregate until after the inversion or iterative procedures. ADOTMATR requires that there be a maximum of 150 sectors at the point of matrix inversion and therefore requires some sector definitions by the user. IMPLAN has a routine which allows the user to define sectors. In terms of sector disaggregation available from the models, RIMS II has sectors identical to the national model and also a version with aggregated rows. IMPLAN is similar but has more aggregation in agriculture and construction and more detail in the mining sectors; RSRI has more detail than the national model in the retail trade sectors.

All of the models follow the BEA conventions for secondary products. ${ }^{18}$ However, IMPLAN and ADOTMATR allow the user to choose other methods if data are available. All models have industry-by-industry frameworks for their results although SCHAFFER uses industry-by-commodity in construction of his tables.

Regionalizing the technological coefficients table is accomplished by adjusting for four potentially unique regional characteristics: product mix, consumption, trade patterns and technology. By remaining at an over 500 sector level of disaggregation, RIMS II, RSRI, and SCHAFFER can justify assuming there is no difference in product mix between the region and the nation. ADOTMATR uses employment weights to aggregate sectors and IMPLAN first creates a regional transactions table.
When adjusting for regional differences in consumption, RIMS II makes commuting adjustments for the household row and then savings and state tax adjustments for the column; RSRI takes adjustments using the BLS regional consumer expenditure survey data; and IMPLAN adjusts consumption to be consistent with gross regional personal consumption data.

All of the models make some effort to allow for difference in regional trade patterns. RIMS II uses a mixed location quotient approach which is facilitated by the fact that they have access to employment and earnings data that is not subject to standard disclosure problems. Both IMPLAN and SCHAFFER use supplydemand pool methodology; however, Schaffer modifies his by using Census of Transportation data to identify exports and imports. RSRI uses the RPC methodology and IMPLAN will adopt this method in their next version. ADOTMATR enables the user to choose between location quotient, supply-demand pool and RPC techniques depending on the data supplied. The default would be to use employment data supplied for sector weighting and estimate location quotients.

With respect to technology differences, none of the models specifically adjust for this factor. However, IMPLAN will adjust the technicai coefficients to agree with regional factor payments data and/or allow the user to specify an industry's technical coefficients by introducing new data. ADOTMATR has a routine to allow user input of specifically known industry technology.

Once a regional table is established, the models use them differently to estimate and present total regional impacts of a given change. Both RIMS II and IMPLAN use the inversion technique to determine the indirect effects, but IMPLAN then uses a different method to estimate the induced effects. RSRI and SCHAFFER both use the iterative approach, and, rather than providing a total requirements table to the user, they provide a full estimate of the specific round-byround impacts of the given change, essentially a summation of all the relevant columns of the table multiplied by the magnitude of the change in final demand for that sector. ADOTMATR allows the user to choose between the inversion and the iterative approach.

The differences in methodology lead to differences in the measures and information available to the users of each model. Table 3 presents the types of multipliers that are estimated and made available to the users of each model. Definitions used in Table 3 include: Type I measurers refer to those which indicate the total effect of direct and indirect requirements; Type II measures include direct, indirect and induced 
requirements (spending of income earned producing direct and indirect requirements); Income Retention Coefficient refers to the total income expected to be retained in the region per dollar of change in final demand; Employment Creation Coefficient refers to the total number of new jobs expected to be created per dollar of change in final demand.

It may be interesting to note that although RSRI does not provide a full total requirements table, it does supply a disaggregated column of impacts for employment, wages, output, value added, occupation and pollution. It also supplies TYPE II income, final demand, output and employment multipliers. RIMS II, IMPLAN and ADOTMATR all provide a total requirements table, but IMPLAN's is only Type I; RIMS II has only Type II; and ADOTMATR includes both. Only RIMS II routinely supplies the user with both an income retention coefficients table and an employment creation coefficients table (theirs are Type II, although IMPLAN does have a Type I for income and II for employment). Only ADOTMATR and IMPLAN provide Type I and II income and employment multipliers, with only IMPLAN including Type III income multipliers. ADOTMATR has added Supply and Output Only multipliers and RSRI supplies a Value Added multiplier.

In general, RIMS II, ADOTMATR and IMPLAN provide the tables for users to estimate their own impacts from given changes. RSRI and SCHAFFER do not routinely provide the tables of coefficients or multipliers, but rather, do the analysis within the model and supply the user with lists of impacts that are associated with specific vectors of expenditures or final demand changes that have been experienced or hypothesized. SCHAFFER and IMPLAN have the most emphasis on identifying the initial changes -- to the point of encouraging surveys to identify the detailed vectors of change. RSRI provides measures of many different kinds of impacts such as pollution and occupations.

Overall, the models have some differences in trade pattern regionalizing methods, sectoring schemes, the choice of iterative or inversion technique, and the way to allow for regional differences in consumption. At the same time, the reference economies, base years, number of disaggregated sectors, conventions for dealing with secondary products and industry-by-industry structure are all similar. The major differences are in packaging and in the type of interaction necessary with the user. The only differences in methodology that would be expected to lead to differences in estimated impacts would be the different regionalizing procedures and the difference in handling and defining the household row and column. The differences would be hypothesized to show up most in measures which included induced effects and those where estimates of imports would be expected to be significant.

\section{Implications for Future Research}

As noted earlier it would be most helpful to expand the scope of the comparison to include a wider range of modeling systems. Such a comparison could include linked econometric systems and community impact systems. It could also be fruitful to compile a complete list of all models available to public users, the costs entailed in using each and the nature of the product supplied by each.

Since both researchers and users alike are interested in the estimates produced by these systems, a logical extension of this study is to compare the estimates made by the five models for some given changes in final demand in various sectors and regions of the country. Such a study is currently underway.

In the on-going search for efficiency it could be useful to identify data sets currently being generated by several or many modelers across the country and work toward the collection and/or manipulation of such data only one time with subsequent availability to all for a price. Not only would this eliminate existing duplication of effort, but it might help to standardize terminology and data definition.

\section{Summary}

The development of a well-organized market for regional input-output models has made changes in the quantity and quality of regional input-output analyses that will be undertaken. Information provided in this paper may foster the growth of the market and the quality of the products.

The differentiation of products in this market will make it appealing to many demanders who at first balked at the use of such a "ready-made" model with complaints of lack of quality. The skeptics claimed only a model developed by local researchers was likely to be accurate. Analysts now have a wide range of choice in this market, from buying detailed lists of impacts in a report to buying a software package that is a shell into which the local user inputs all the data but need not program to get multipliers and impacts. In such an environment, users benefit from more information about the market whatever their goal. A user proficient at programming and modeling himself, may even begin to participate in the market by supplying his model to others. In each case some 

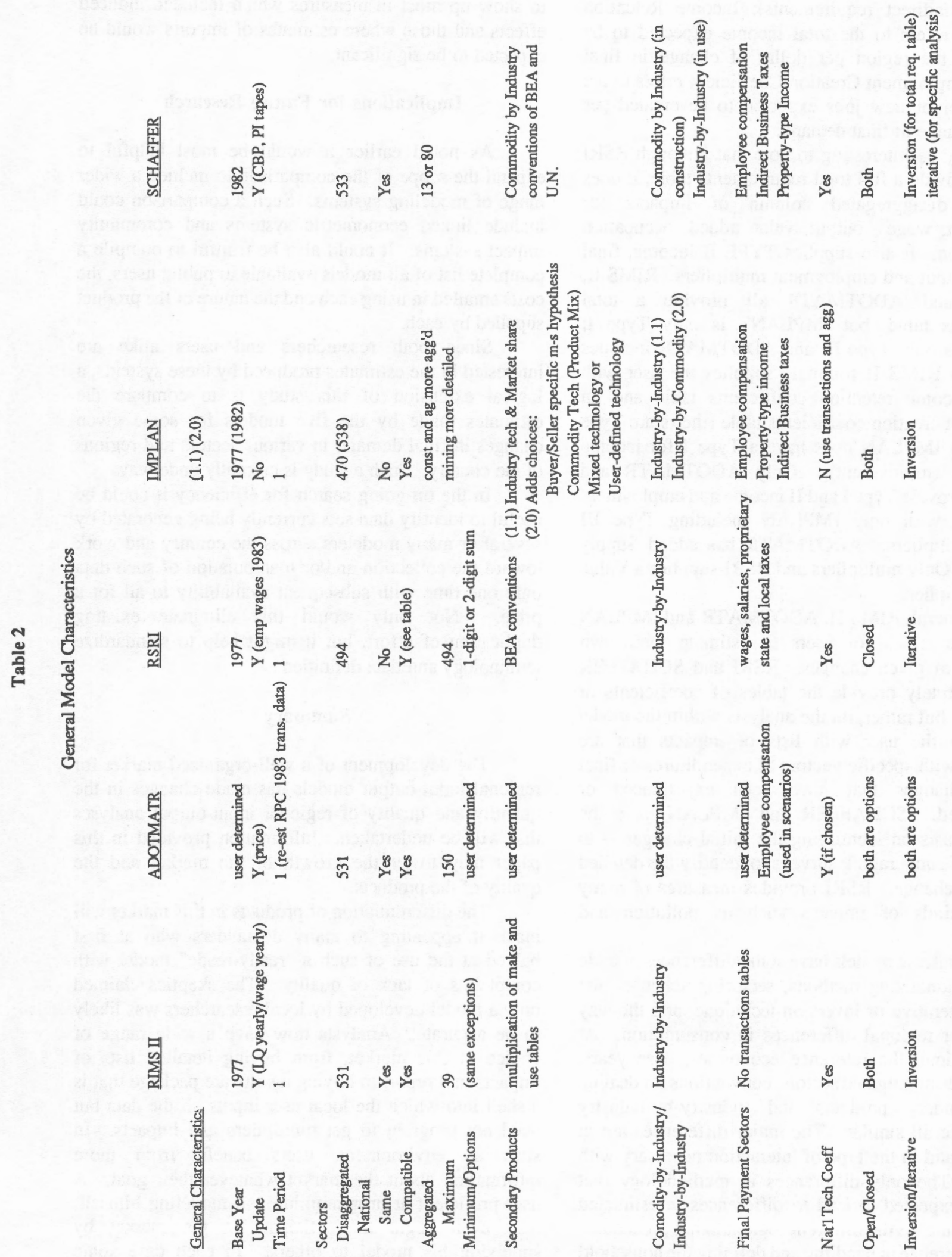


溒国

$>$

$* * * * z$

$* *$

㜥



象会

월일

z $\quad$ z

z $z \quad z$

กัّ

氞

$z$

z

$z \quad z$

z

z

$z>z$

z $\quad$ z

氞国

$\approx \nabla$

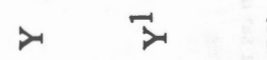

美

氙

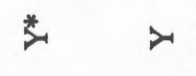

z

Z

z

z z

美

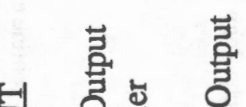



:

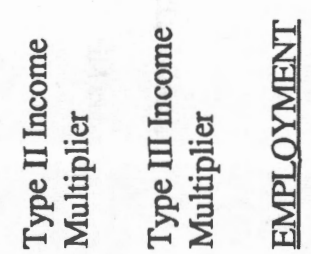

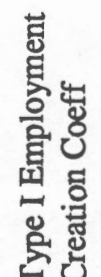

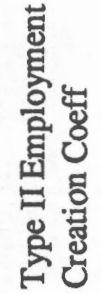




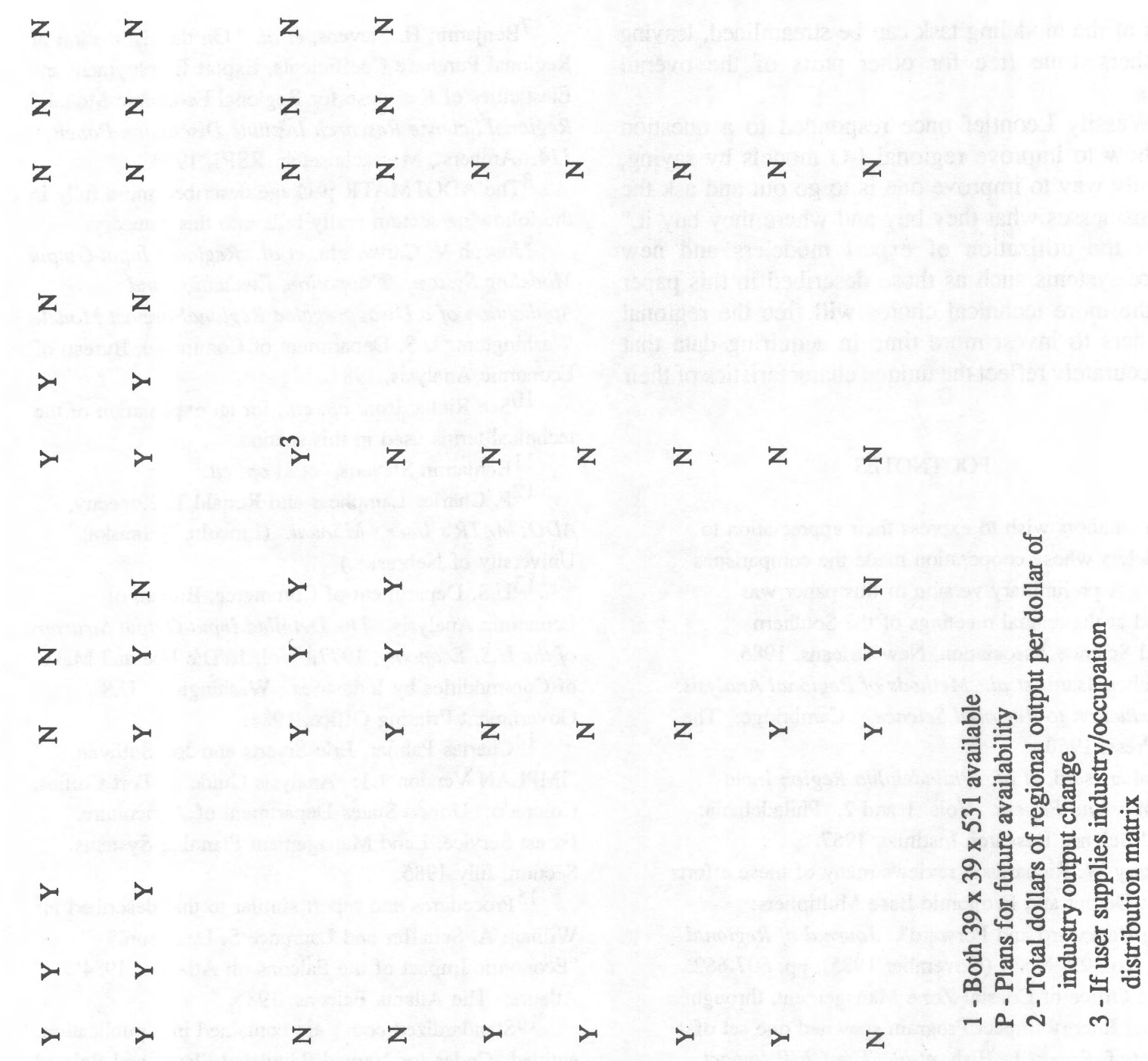
* 艾
$\begin{array}{lllllllll}\mathbf{z} & \mathbf{z} & \mathbf{z} & \mathbf{z} & \mathbf{z} & \mathbf{z} & \mathbf{z} & \mathbf{z} & \mathbf{z}\end{array}$
$>\quad z \quad z$

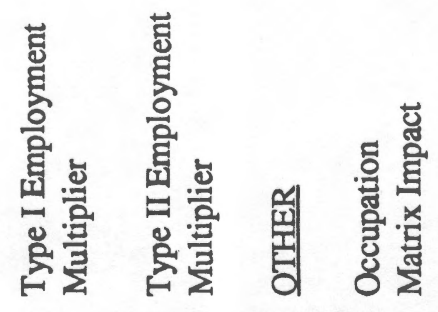



